\title{
Kajian Strategi Pemasaran Ubi Cilembu \\ (Kasus di Desa Cilembu, Kecamatan Pamulihan, Kabupaten Sumedang)
}

\author{
Study on the Strategic Marketing of Honey Sweet Potatoes "Cilembu" \\ (Case Study in Cilembu Village, Pamulihan Subdistrict, Sumedang District)
}

\author{
Cordelia Ervina ${ }^{1 *}$, Musa Hubeis ${ }^{2 *}$, dan Nora H. Pandjaitan ${ }^{3 *}$
}

${ }^{1}$ Kementerian Pertanian

Jl. Harsono RM No. 3 Ragunan, Pasar Minggu, Jakarta Selatan, DKI Jakarta

${ }^{2}$ Departemen Manajemen, Fakultas Ekonomi Manajemen Institut Pertanian Bogor

${ }^{3}$ Departemen Teknil Sipil dan Lingkungan, Fakultas Teknologi Pertanian Institut Pertanian Bogor

\# Jl. Kamper, Kampus IPB Dramaga, Bogor 16680

\begin{abstract}
ABSTRAK
Salah satu daerah penghasil ubi jalar adalah Desa Cilembu yang berada di Kecamatan Pamulihan, Kabupaten Sumedang. Tujuan penelitian mengidentifikasi faktor internal dan eksternal yang memengaruhi ketersediaan bahan baku dan kontinuitas sistem pemasaran ubi Cilembu dan merekomendasikan alternatif strategi pemasaran efektif dan efisien untuk memasarkan ubi Cilembu yang dihasilkan unit usaha Kelompok Agribisnis Ubi Jalar Cilembu Pelopor (KUCP). Penelitian ini menggunakan teknik purposive sampling dan dukungan data primer dan sekunder. Responden sebanyak 30 orang dari 107 petani ubi Cilembu di Desa Cilembu. Analisis dilakukan dengan matriks IFE (internal factor evaluation) dan EFE (eksternal factor evaluation), matriks internal-eksternal (IE), SWOT (Strong, Weaknesses, Opportunities, Threats) dan QSPM (Quantitative Strategic Planning Matrix) . Dari beberapa strategi yang dihasilkan, satu strategi prioritas didapatkan melalui analisis QSPM diharapkan mampu mendongkrak pemasaran ubi Cilembu oleh KUCP. Strategi tersebut adalah mendorong upaya-upaya penciptaan usaha pengolahan skala kecil menengah ubi cilembu untuk mendapatkan produk-produk olahan yang berdaya saing.
\end{abstract}

Kata kunci: strategi pemasaran, strategi prioritas, ubi cilembu

\section{ABSTRACT}

One of areas which producing sweet potato is Cilembu Village, located in Pamulihan Subdistrict, Sumedang Regency. The sweet Potato is famous as ubi Cilembu. The objectives of this research were to identify internal and external factors affecting raw material availability and continuity of marketing system of sweet potato Cilembu and to recommend alternative of effective and efficient marketing strategy of sweet potato Cilembu. This research used purposive sampling and also primary and secondary data. Respondents consisted of 30 people from 107 population of sweet potatoes Cilembu in Cilembu village. Analysis was conducted using IFE and EFE matrix, internal-external (IE) matrix, SWOT and QSPM method. From several strategies by using QSPM method, it had chosen one strategy to boost Cilembu sweet potato marketing by KUCP. The strategy was to encourage efforts in creating processing business medium scale of Cilembu sweet potatoes in order to get competitive processed products.

Key words: marketing strategy, priority strategy, ubi Cilembu

\section{PENDAHULUAN}

Pertanian masih merupakan sektor penting dalam perekonomian Indonesia. Sektor pertanian telah berperan besar dalam pembangunan Produk
Domestik Bruto (PDB) Nasional hingga mencapai $13-14 \%$. Sektor agribisnis (pertanian, industri dan jasa pertanian) menyumbangkan $45 \%$ dari total nilai tambah, menyerap $75 \%$ tenaga kerja, penyedia pangan, dan tempat bergantung sebagian besar

\footnotetext{
*) Korespondensi:

Jl. Kencana I, Kencana Asri Town House C03 Kalimulya, Cilodong, Depok; email: cordeliaervina@yahoo.com
} 
penduduk pedesaan. Peran ini akan bertambah di masa mendatang dengan berkembangnya teknologi dan berkurangnya sumber daya tak terbarukan, yakni pertanian menjadi tumpuan penyedia pangan yang makin beragam (food), pakan yang semakin bertambah (feed) dan alternatif energi (Mentan, 2010).

Meningkatnya jumlah penduduk Indonesia sejalan dengan meningkatnya kebutuhan pangan nasional, maka ketergantungan hanya pada satu sumber pangan, yaitu beras akan menimbulkan masalah serius bagi bangsa Indonesia, terutama ketahanan pangan nasional. Salah satu upaya mengantisipasi ketersediaan pangan adalah menggalakkan kembali pemahaman mengenai konsep diversifikasi pangan. Diversifikasi pangan berarti penganekaragaman produksi tanaman non beras, khususnya palawija. Lebih khusus lagi, diversifikasi pangan berarti peningkatan produksi cepat dari tanaman palawija utama, seperti ubi kayu, jagung dan ubi jalar (Sari, 2004).

Salah satu sentra terbesar produksi ubi jalar di Indonesia adalah Propinsi Jawa Barat (Maulana et al, 2011). Dari sekian banyak jenis ubi jalar yang ada di Jawa Barat, ada jenis ubi jalar yang cukup istimewa dibandingkan umbi-umbi sejenisnya. Salah satu daerah penghasil ubi jalar ini adalah Desa Cilembu yang berada di Kecamatan Pamulihan, Kabupaten Sumedang. Ubi Jalar ini terkenal dengan sebutan Ubi Cilembu, rasanya sangat manis dan aromanya yang khas telah menjadikan ubi jalar ini terkenal di Indonesia.

Pengembangan ubi jalar Cilembu sudah berjalan lama, namun secara ekonomi, belum memberikan nilai tambah nyata kepada petani maupun kepada pelaku usaha olahan. Hal ini disebabkan kesinambungan produksi belum optimal, sehingga ketersediaan pasokan dan kontinuitas kepada pedagang atau perusahaan pengolah menjadi tidak terjamin, yang akhirnya memengaruhi sistem pemasaran berkelanjutan.

Berdasarkan permasalahan yang dihadapi dalam pelaksanaan pemasaran ubi jalar Cilembu, maka dilakukan penelitian yang bertujuan mengidentifikasi faktor internal dan eksternal yang memengaruhi ketersediaan bahan baku, serta kontinuitas sistem pemasaran ubi jalar Cilembu dan merekomendasikan alternatif strategi pemasaran efektif dan efisien untuk memasarkan ubi jalar Cilembu yang dihasilkan unit usaha Kelompok Agribisnis Ubi Jalar Cilembu Pelopor (KUCP).

\section{METODE PENELITIAN}

\section{Pengumpulan Data}

Pengumpulan data yang diperoleh dari data sekunder maupun primer hasil wawancara dan kuesioner dilakukan dengan analisis deskriptif untuk mendapatkan informasi lebih mendalam tentang obyek penelitian (Rangkuti, 2006). Jenis data yang dikumpulkan adalah data primer dan sekunder. Untuk data primer dilakukan observasi lapangan kepada 30 orang KUCP dari 107 populasi petani ubi Cilembu di Desa Cilembu. Metode pengambilan contoh dan res-ponden yang dipilih dalam penelitian ini menggunakan purposive sampling, yaitu teknik penentuan contoh dengan pertimbangan tertentu (Sugiyono, 2012).

\section{Pengolahan dan Analisis Data}

Pengolahan dan analisis data meliputi analisis kualitatif, dimana data yang telah terkumpul dideskripsikan atau digambarkan sebagaimana adanya. Dalam tahap wawancara, responden mengidentifikasi dan mengevaluasi serta memberikan bobot dan rating terhadap faktor-faktor strategik yang diuraikan dalam kuesioner. Data yang dianalisis merupakan data ordinal seperti data internal dan eksternal KUCP yang merupakan faktor kunci dan berpengaruh terhadap perkembangan KUCP. Data yang terkumpul selanjutnya dianalisis dengan matriks IFE (internal factor evaluation) dan EFE (external factor evaluation), matriks internal-eksternal (IE), SWOT (Strength, Weaknesses, Opportunities, Threats) dan QSPM (quantitative strategic planning matrix).

Matriks EFE digunakan menganalisis faktorfaktor eksternal, atas peluang dan ancaman bagi kelompok usaha tani, kemudian dilakukan pembobotan. Matriks IFE digunakan menganalisis faktor-faktor internal, mengklasifikasikannya atas kekuatan dan kelemahan kelompok usaha tani, kemudian dilakukan pembobotan (Hutagaol et al, 2008).

Analisis SWOT digunakan untuk menyusun faktor-faktor strategi perusahaan yang meng-gambarkan secara jelas hubungan peluang dan ancaman eksternal yang dihadapi perusahaan (Hero et al, 2008). Analisis SWOT dan QSPM merupakan alat analisis dalam menentukan formula strategik pengembangan usaha. Formula strategik disusun dengan menggabungkan berbagai indikator yang terdapat dalam kekuatan, kelemahan, peluang dan ancaman. Model penggabungannya menggunakan matriks. Strategi yang dipilih 
adalah strategi yang dapat memecahkan isu strategik perusahaan (Singka et al, 2014).

\section{HASIL DAN PEMBAHASAN}

KUCP adalah Kelompok usaha tani beranggotakan para petani produsen dan pedagang ubi Cilembu. Pendirian kelompok bertujuan membantu para petani, pedagang dan konsumen ubi Cilembu dalam memperoleh manfaat nyata dari komoditas ubi Cilembu. KUCP terdiri dari 107 orang yang terdiri dari anggota dan pengurus. Luas lahan 25 ha dan beralamat di Desa Cilembu No. 49 RT 02/RW09, Kec. Pamulihan Kabupaten Sumedang, Jawa Barat. Kelompok tani ini bermitra usaha dengan kelompok tani lain dan perusahaan eksportir CV Techtar Farm and Food. Produksi sebesar 40 ton/bulan dan mempunyai volume ekspor 30 ton/bulan. Komoditi yang diusahakan KUCP adalah ubi Cilembu mentah dan matang.

KUCP memiliki visi menjadi wadah masyarakat petani dan menjadi mitra pemerintah dalam pengembangan Agrobisnis di wilayah Jawa Barat. Untuk merealisasikan visinya, KUCP memiliki misi:

1. Membantu pemerintah Kabupaten Sumedang dan Propinsi Jawa Barat dalam akselerasi pencapaian visi dan misi pembangunan.

2. Menghimpun kelompok tani dan memfasilitasi pembentukan Koperasi Petani ubi Cilembu, menyelenggarakan diklat, penelitian dan pengembangan (litbang) agrobisnis.

3. Membina petani produsen dalam teknologi budidaya dan membina pedagang dalam pengolahan, serta pemasaran ubi Cilembu

4. Memfasilitasi usulan hak kekayaan intelektual (HKI)/paten untuk varietas dan hasil olahan ubi Cilembu dalam rangka melindungi konsumen dari pemalsuan.

5. Memfasilitasi promosi dan pengembangan pemasaran di dalam dan luar negeri.

Saat ini, pemasaran ubi Cilembu dilakukan di kios-kios daerah Cilembu, dan disepanjang jalan raya Sumedang. Ubi Cilembu dipasarkan di kotakota besar seperti Bandung, Jakarta, Tangerang, Jawa Tengah, Jawa Timur, Bali, Lampung, Riau, Sumatera Selatan, bahkan sampai ke luar negeri seperti Singapura, Hongkong dan Jepang.

\section{Matriks IFE/EFE}

Langkah ringkas dalam melakukan audit manajemen strategik adalah membuat matriks IFE.

Vol. 14 No. 1
Alat perumusan strategi ini meringkas dan mengevaluasi kekuatan dan kelemahan utama dalam berbagai bidang fungsional dalam suatu organisasi (Ilyas et al, 2016). Matriks ini menjadi landasan mengidentifikasi dan mengevaluasi hubungan diantara bidang-bidang ini. Penilaian intuitif diperlukan dalam membuat matriks IFE. Pemahaman mendalam mengenai faktor-faktor yang dimuat dalam matriks ini lebih penting dari sekedar angka-angka. Seperti halnya matriks EFE, matriks IFE dapat dikembangkan seperti ditunjukkan pada Tabel 1.

Tabel 1. Matriks IFE

\begin{tabular}{|c|c|c|c|}
\hline \multirow[t]{2}{*}{ Faktor-faktor intenral } & Bobot & Rating & $\begin{array}{l}\text { Skor } \\
\text { total }\end{array}$ \\
\hline & (a) & (b) & $(a x b)$ \\
\hline \multicolumn{4}{|l|}{ A. Kekuatan } \\
\hline $\begin{array}{l}\text { Penerapan GHP yang } \\
\text { sudah on sistem }\end{array}$ & 0,119 & 4,0 & 0,474 \\
\hline Ubi ilembu sudah dikenal & 0,091 & 3,5 & 0,317 \\
\hline $\begin{array}{l}\text { Sarana dan prasarana } \\
\mathrm{KUCP}\end{array}$ & 0,094 & 3,25 & 0,307 \\
\hline Komoditi ekspor & 0,094 & 0,350 & 0,331 \\
\hline $\begin{array}{l}\text { Indeigenous soil ubi } \\
\text { Cilembu }\end{array}$ & 0,101 & 3,75 & 0,380 \\
\hline $\begin{array}{l}\text { Diersifikasi produk } \\
\text { olahan ubi jalar Cilembu }\end{array}$ & 0,082 & 3,25 & 0,266 \\
\hline Sub total A & & & 2,074 \\
\hline \multicolumn{4}{|l|}{ B. Kelemahan } \\
\hline Rendahnya produktivitas & 0,096 & 1,50 & 0,144 \\
\hline $\begin{array}{l}\text { Kurangnya kontinuitas } \\
\text { produk (tidak konstan) }\end{array}$ & 0,082 & 2,00 & 0,164 \\
\hline $\begin{array}{l}\text { Promosi daam negeri } \\
\text { terbatas }\end{array}$ & 0,077 & 2,00 & 0,154 \\
\hline $\begin{array}{l}\text { Biaya promosi KUCP } \\
\text { terbatas }\end{array}$ & 0,071 & 2,00 & 0,143 \\
\hline $\begin{array}{l}\text { Pemasaran dan } \\
\text { pengolahan ubi Cilembu } \\
\text { belum optimal }\end{array}$ & 0,092 & 2,00 & 0,185 \\
\hline Sub total B & & & 0,790 \\
\hline Total $(\mathrm{A}+\mathrm{B})$ & & & 2,864 \\
\hline
\end{tabular}

Berdasarkan identifikasi dari matriks IFE, diiketahui bahwa kekuatan KUCP adalah penerapan GHP yang sudah konsisten (nilai 0,474). Dengan penerapan GHP yang sudah konsisten maka KUCP dapat memenuhi ketersediaan ubi Cilembu sesuai syarat mutu dan permintaan produk secara konsisten dan berkesinambungan. Dengan demikian, sebagai unit usaha, seyogyanya KUCP dapat menjalankan usahanya yang memberikan prospek baik. Namun hal tersebut tidak demikian adanya, karena ada beberapa kelemahan yang memengaruhi ketersediaan ubi Cilembu, salah satunya rendahnya produktivitas (nilai 0,44 )

Februari 2019 
yang berbanding lurus dengan produksi ubi Cilembu. Dengan rendahnya produktivitas, maka bisa diasumsikan penerapan Good Agricultural Practises (GAP) pada KUCP belum optimal.

Matriks EFE disusun agar perencana strategi dapat meringkas dan mengevaluasi informasi berdasarkan indikator-indikator yang masuk dalam faktor eksternal yaitu dari sisi peluang dan ancaman. Hasil perhitungan matriks EFE yang dirangkum dari penilaian para pakar menghasilkan analisis seperti terlihat pada Tabel 2.

Tabel 2. Matriks EFE

\begin{tabular}{|c|c|c|c|}
\hline \multirow[t]{2}{*}{ Faktor-faktor internal } & Bobot & Rating & $\begin{array}{l}\text { Skor } \\
\text { total }\end{array}$ \\
\hline & (a) & (b) & $(\mathrm{axb})$ \\
\hline \multicolumn{4}{|l|}{ Peluang } \\
\hline Kemajuan teknologi & 0.110 & 3,75 & 0,413 \\
\hline $\begin{array}{l}\text { Pengolahan ubi jalar } \\
\text { Cilembu }\end{array}$ & 0,101 & 3,00 & 0,303 \\
\hline $\begin{array}{l}\text { Pansa pasar ubi jalar } \\
\text { Cilembu masih terbuka } \\
\text { luas }\end{array}$ & 0,112 & 4,00 & 0,449 \\
\hline $\begin{array}{l}\text { Investasi usaha ubi jalar } \\
\text { Cilembu }\end{array}$ & 0,100 & 3,75 & 0,375 \\
\hline $\begin{array}{l}\text { Program pemerintah } \\
\text { (diversifikasi pangan) }\end{array}$ & 0,113 & 3,75 & 0,425 \\
\hline Sub total A & & & 1,965 \\
\hline \multicolumn{4}{|l|}{ Ancaman } \\
\hline Pasar bebas ASEAN & 0,098 & 1,50 & 0,147 \\
\hline Alih fungsi lahan & 0,100 & 1,00 & 0,100 \\
\hline $\begin{array}{l}\text { Proses penetapan harga di } \\
\text { tingkat petani }\end{array}$ & 0,098 & 1,25 & 0,122 \\
\hline $\begin{array}{l}\text { Keberadaan ubi jalar } \\
\text { Cilembu sejenis }\end{array}$ & 0,073 & 1,75 & 0,128 \\
\hline Sub total B & & & 0,663 \\
\hline Total $(\mathrm{A}+\mathrm{B})$ & & & 2,627 \\
\hline
\end{tabular}

Berdasarkan hasil identifikasi matriks EFE dengan nilai skala 1-4, diperoleh nilai skor total peluang $(\mathbf{1}, 965)$ lebih besar dari skor ancaman $(\mathbf{0}, 663)$. Nilai ini menjelaskan peluang lebih besar dibandingkan dengan ancaman, sehingga jika peluang tersebut dapat dimanfaatkan dengan baik, maka akan memengaruhi ketersediaan dan kontinuitas ubi Cilembu.

Tabel 2 menunjukkan peluang yang dimiliki ubi jalar Cilembu adalah pangsa pasarnya masih terbuka luas (nilai 0,449 ) dan adanya program Pemerintah berupa diversifikasi pangan (nilai 0,425), dimana KUCP bisa memanfaatkan peluang untuk terus berupaya memenuhi ketersediaan ubi Cilembu secara berkelanjutan. Sementara itu, ancaman yang timbul berasal dari hama penyakit. Faktor hama penyakit ini memengaruhi produk- tivitas secara nyata. Dengan nilai 0,165 , serangan hama penyakit merupakan faktor eksternal yang sangat kuat memengaruhi ketersediaan ubi Cilembu dan memengaruhi sistem pemasaran ubi Cilembu KUCP. Selain serangan hama penyakit, alih fungsi lahan yang semakin intensif juga berpengaruh langsung terhadap produksi dan ketersediaan pasokan ubi Cilembu. Dengan teridentifikasinya faktor internal dan eksternal yang memengaruhi ketersediaan dan pemasaran ubi Cilembu tersebut, maka diperlukan strategi mengatasi beberapa kelemahan dan ancaman KUCP.

Dari total nilai pada matriks internal 2,864 dan total nilai matriks eksternal 2,627, maka posisi KUCP berada pada sel $\mathrm{V}$, yaitu posisi sedang atau rataan (Gambar 1). Strategi disarankan untuk diterapkan pada kondisi tersebut adalah strategi penetrasi pasar dengan cara meningkatkan promosi pengembangan produk olahan yang berbahan dasar ubi Cilembu (Indriawati et al, 2011).

Setelah mengetahui posisi KUCP, maka disusun faktor-faktor strategi bagi KUCP dengan menggunalkan matriks SWOT. Nilai skor skor peluang $(\mathbf{1}, 965)$ lebih besar dari skor ancaman $(\mathbf{0 , 6 6 3 )}$ dan nilai skor kekuatan 2,074 lebih besar dari skor kelemahan $\mathbf{0 , 7 9 0}$. Untuk itu, strategi yang disarankan adalah Strategi S-O (strengths)Opportunities). Strategi SO merupakan strategi yang dibuat berdasarkan jalan pemikiran obyek, yaitu menggunakan seluruh kekuatan untuk merebut dan memanfaatkan peluang sebesarbesarnya. Keempat strategi tersebut dipetakan ke dalam Matriks SWOT (Tabel 3) untuk mendapatkan gambaran keseluruhan atas alternatif strategi yang dapat dipilih untuk pemasaran Ubi Cilembu.

\section{Perencanaan Strategi Kumulatif}

Tahap terakhir dalam perumusan alternatif strategi setelah sebelumnya memilih beberapa alternatif strategi adalah melakukan pengambil-an keputusan memilih strategi yang paling tepat bagi KUCP dengan matriks QSPM.

Berdasarkan hasil perhitungan TAS, alternatif strategi yang paling diminati dan diprioritaskan untuk dilakukan oleh KUCP adalah mendorong upaya-upaya penciptaan usaha pengolahan skala kecil menengah ubi Cilembu untuk mendapatkan produk-produk olahannya yang berdaya saing. Pelaksanaan alternatif strategi berdasarkan nilai TAS pada QSPM dapat dilakukan dari nilai TAS strategi yang terkecil. Pilihan prioritas alternatif strategi dari matriks SWOT dimuat pada Tabel 4 
TOTAL SKOR FAKTOR STRATEGI INTERNAL

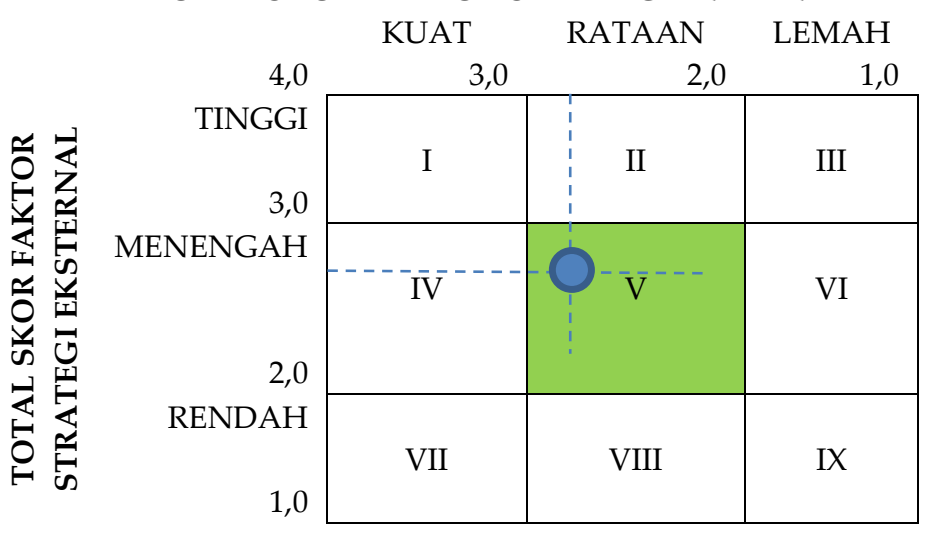

Gambar 1. Matriks IE

Tabel 3. Matriks SWOT

\begin{tabular}{|c|c|c|}
\hline Faktor eksternal & $\begin{array}{l}\text { Kekuatan (Strength-S) } \\
\text { 1. Penerapan GHP yang sudah on } \\
\text { sistem } \\
\text { 2. Ubi Cilembu sudah dikenal } \\
\text { 3. Sarana dan prasarana KUCP } \\
\text { 4. Komoditi ekspor } \\
\text { 5. Indeigenous soil ubi Cilembu } \\
\text { 6. Diersifikasi produk olahan ubi } \\
\text { jalar Cilembu }\end{array}$ & $\begin{array}{l}\text { Kelemahan (Weakness-W) } \\
\text { 1. Rendahnya produktivitas } \\
\text { 2. Kurangnya kontinuitas produk } \\
\text { (tidak konstan) } \\
\text { 3. Promosi daam negeri terbatas } \\
\text { 4. Biaya promosi KUCP terbatas } \\
\text { 5. Pemasaran dan pengolahan ubi } \\
\text { Cilembu belum optimal }\end{array}$ \\
\hline $\begin{array}{l}\text { Peluang (opportunity-O) } \\
\text { 1. Kemajuan teknologi } \\
\text { 2. Pengolahan ubi jalar Cilembu } \\
\text { 3. Pansa pasar ubi jalar } \\
\text { Cilembu masih terbuka luas } \\
\text { 4. Investasi usaha ubi jalar } \\
\text { Cilembu } \\
\text { 5. Program pemerintah } \\
\text { (diversifikasi pangan) }\end{array}$ & \begin{tabular}{ll}
\multicolumn{1}{c}{ Strategi SO } \\
1. & Meningkatkan promosi ubi \\
Cilembu di berbagai media \\
dalam dan luar negeri (S1,S2,S3; \\
O3,O5) \\
2. Mempertahankan konsistensi \\
GHP di lapangan (S1,S4; O2,O3) \\
3. Mendorong investasi produk \\
olahan ubi Cilembu di tingkat \\
pedesaan (S1,S2,S4,S5; O5,O4,O5)
\end{tabular} & \begin{tabular}{l}
\multicolumn{1}{c}{ Strategi WO } \\
1. Mengoptimalkan promosi \\
melalui website, media sosial, \\
atau media elektronik lainnya \\
(W3,W4,W5; O1) \\
2. Menjalin kerjasama dengan \\
supermarket modern dan biro \\
perjalanan di daerah Sumedang \\
dan wilayah Jawa Barat lainnya \\
(W3,W4,W5; O1,O3)
\end{tabular} \\
\hline $\begin{array}{l}\text { Ancaman (Threats-T) } \\
\text { 1. Pasar bebas ASEAN } \\
\text { 2. Alih fungsi lahan } \\
\text { 3. Proses penetapan harga di } \\
\text { tingkat petani } \\
\text { 4. Keberadaan ubi jalar } \\
\text { Cilembu sejenis }\end{array}$ & $\begin{array}{l}\text { Strategi ST } \\
\text { 1. Mendorong pemerintah daerah } \\
\text { untuk membuat regulasi alih } \\
\text { fungsi lahan dalam rangka } \\
\text { mempertahankan eksistensi ubi } \\
\text { Cilembu (S5; T2) } \\
\text { 2. Mendorng transparansi sistem } \\
\text { jual beli antara pedagang dan } \\
\text { petani (S3; T3) } \\
\text { 3. Memberdayakan lembaga } \\
\text { ekonomi petani dengan } \\
\text { memperkuat permodalan } \\
\text { melalui kredit usaha tani } \\
\text { berbunga rendah (S3; T3) }\end{array}$ & $\begin{array}{l}\text { Strategi WT } \\
\text { 1. Mengembangkan komoditas } \\
\text { varietas unggul ubi Cilembu } \\
\text { dengan penelitian untu } \\
\text { mendapatkan solusi penanaman } \\
\text { yang efektif dan berkelanjutan } \\
\text { melalui kerjasama Pemerintah } \\
\text { Daerah, Pemerintah Pusat dan } \\
\text { universitas (W1,W2; T4,T5) } \\
\text { 2. Mendorong upaya-upaya } \\
\text { penciptaan usaha pengolahan } \\
\text { skala kecil menengah untuk } \\
\text { mendapatkan produk-produk } \\
\text { olahan yang berdaya saing } \\
\text { (W5; T1,T5) }\end{array}$ \\
\hline
\end{tabular}


Tabel 4. Peringkat Alternatif Strategi Pemasaran Ubi Cilembu pada KUCP di desa Pamulihan, Kabupaten Sumedang

\begin{tabular}{llcr}
\hline & \multicolumn{1}{c}{ Strategi } & $\begin{array}{c}\text { Nilai } \\
\text { total }\end{array}$ & Prioritas \\
\hline Strategi 4 & $\begin{array}{l}\text { Mendorong upaya-upaya penciptaan usaha pengolahan skala kecil } \\
\text { menengah untuk mendapatkan produk-produk olahan yang berdaya saing }\end{array}$ & 6,819 & 1 \\
Strategi 5 & $\begin{array}{l}\text { Memberdayakan lembaga ekonomi petani dengan memperkuat } \\
\text { permodalan melalui kredit usaha tani berbunga rendah } \\
\text { Strategi } 2\end{array}$ & $\begin{array}{l}\text { Menjalin kerjasama dengan supermarket modern dan biro perjalanan di } \\
\text { daerah Sumedang dan wilayah Jawa Barat lainnya }\end{array}$ & 6,275 \\
Strategi 3 & $\begin{array}{l}\text { Mendorong Pemerintah Daerah untuk membuat regulasi alih fungsi lahan } \\
\text { dalam rangka mempertahankan eksistensi ubi Cilembu }\end{array}$ & 6,176 & 4 \\
Strategi 1 & $\begin{array}{l}\text { Meningkatkan promosi ubi Cilembu di berbagai media dalam dan luar } \\
\text { negeri }\end{array}$ & 6,161 & 5 \\
\hline
\end{tabular}

Dari analisis SWOT (potret) dan QSPM (prioritas), didapatkan tema yang serupa, tetapi dengan penekanan berbeda yaitu $\geq 6.500$, dimana prioritas strategi didasarkan pada pengelompokkan tema produk, modal, kemitraan, regulasi dan pasar.

\section{KESIMPULAN}

Hasil analisis faktor internal dan eksternal, didapatkan kekuatan KUCP di desa Pamulihan, Kabupaten Sumedang penerapan GHP yang konsisten, kelemahannya menunjukkan kurangnya produktivitas. Kurangnya atau rendahnya poduktivitas ini merupakan faktor utama yang memengaruhi ketersediaan ubi Cilembu. Rendahnya produktivitas berbanding lurus dengan produksi ubi Cilembu dan berpengaruh pada kontinuitas pemasarannya. Dengan rendahnya produktivitas, maka penerapan GAP pada KUCP belum optimal. Jika GAP dan GHP dilaksanakan secara konsisten, maka hasil produksi akan lebih baik

Faktor lain yang memengaruhi ketersediaan ubi Cilembu adalah serangan hama penyakit yang secara langsung memengaruhi produktivitas dan produksi ubi Cilembu. Alih fungsi lahan perlu mendapat perhatian, karena merupakan faktor lain yang mempengaruhi produksi ubi cilembu di KUCP. Peluang yang dimiliki KUCP adalah kemajuan teknologi yang diharapkan bisa meningkatkan promosi ubi Cilembu dan ancaman yang dihadapi adalah serangan hama penyakit.

Dari beberapa strategi yang dihasilkan, maka salah satu strategi prioritas yang didapatkan melalui analisis QSPM diharapkan mampu mendongkrak pemasaran ubi Cilembu oleh KUCP dengan cara menciptakan usaha pengolahan skala kecil menengah yang menghasilkan produkproduk olahan berdaya saing.

\section{DAFTAR PUSTAKA}

Hero, Y, Sudaryanto, Setyowati. 2008. Strategi Pemasaran Mebel Kayu Sentra Industri kecil Pondok Bambu, Jakarta Timur. Jurnal JMHT, XIV(2): 73-80.

Hutagaol, R.E., H. Hubeis, S.T. Soekarto. 2010. Kajian Strategi Pemasaran Es Krim Baltic di PT Balticindo Jayafood Jakarta. Jurnal Manajemen IKM, 5(2): 122-131.

Ilyas, A, S. Rahardja, T. Muhandri. 2016. Strategi Pemasaran Produk Animasi PT Ayena Mandiri Sinema. Jurnal Manajemen IKM, 11(1): 10-19.

Indriawati, P., S. Rahardja, S.T. Soekarto. 2011. Kajian Strategi Pengembangan Usaha Industri Kripik Singkong Perusaha Inti Sari Rasa di Bekasi. Jurnal Manajemen IKM, 6(2): 99-104.

Maulana, H., R. Waluyo, A. Karuniawan. 2011. Status Ubi Jalar Varietas Neerkom dan Eno di Sentra Produksi Ubi Jalar Cilembu Kabupaten Sumedang. [catatan penelitian] Universitas Jenderal Soedirman, Purwokerto, Jawa Tengah.

[Mentan] Menteri Pertanian. 2010. Blue Print Peningkatan Nilai Tambah dan Daya Saing Produk Pertanian dengan Pemberian Insentif Bagi Tumbuhnya Industri Pedesaan. Peraturan Menteri Pertanian nomor.18/Permentan/OT.140/2/2010 tanggal 5 Februari 2010. Jakarta (ID). Kementerian Pertanian.

Rangkuti, F. 2006. Analisis SWOT: Teknik Membedah Kasus Bisnis. Jakarta (ID). PT Gramedia Pustaka Utama. 
Rukmana, R. 1997. Ubi Jalar, Budidaya dan Pasca Panen. Jakarta (ID). Kanisius.

Sari, E.P. 2004. Analisis Prospek Pengembangan Komoditas Ubi Jalar (Ipomea Batatas) dan Kelayakan Pembangunan Pabrik Frozen French Ubi Jalar di Kabupaten Musi Banyuasin, Sumatera Selatan. [tesis]. Institut Pertanian Bogor.
Singka, F.N., N.K. Pandjaitan, T. Muhandri. 2014. Usaha dan Pengembangan Usaha Kecil Berbasis Komunitas Lokal. Jurnal Manajemen IKM, 9(2): 158-159.

Sugiyono. 2012. Memahami Penelitian Kualitatif. Bandung (ID). PT. Alfabeta. 